\title{
PERCEPÇÃO AMBIENTAL DOS MORADORES DE SÃO JOSÉ DO GOIA- BAL SOBRE O PARQUE ESTADUAL DO RIO DOCE: A INFLUÊNCIA DAS VARIÁVEIS GÊNERO, IDADE, CLASSE SOCIAL E ESCOLARIDADE
}

\author{
Fernanda Aires Ferreira Guedes ${ }^{1}$ \\ Maione Wittig Franco ${ }^{2}$ \\ Paulina Maia-Barbosa ${ }^{3}$ \\ Maria Auxiliadora Drumond ${ }^{4}$ \\ Francisco Antônio Rodrigues Barbosa ${ }^{5}$
}

Resumo: O Parque Estadual do Rio Doce (PERD) foi a primeira unidade de conservação criada em Minas Gerais e é uma das maiores áreas remanescentes de Mata Atlântica no país. O objetivo deste estudo foi investigar em São José do Goiabal, município circunvizinho ao parque, a percepção dos moradores sobre o PERD analisando, através de entrevistas semiestruturadas, a influência de diferentes variáveis. Os dados mostraram que gênero, classe social e idade não determinam a frequência de visitação. A caça a animais silvestres mostrou-se prática comum, reconhecida pela população e motivada principalmente pelo lazer e apreciação da carne. O desenvolvimento de projetos de Educação Ambiental envolvendo alunos da rede básica de educação é o fator que mais influencia o conhecimento e valorização do PERD. Tais constatações sugerem a necessidade da implantação de programas de Educação Ambiental voltados principalmente para crianças e jovens, tornando-os parceiros dos propósitos de conservação da biodiversidade na região.

Palavras-chave: Percepção ambiental. Parque Estadual do Rio Doce. Conservação da biodiversidade regional.

\section{ENVIRONMENTAL PERCEPTION OF RESIDENTS IN SÃO JOSÉ DO GOIABAL ON THE RIO DOCE STATE PARK: THE INFLUENCE OF THE GENDER, AGE, SOCIAL CLASS AND SCHOOLING VARIABLES}

Abstract: The Rio Doce State Park was the first protected area created in the state of Minas Gerais and is one of the largest remnants of the Brazilian Atlantic Forest. Our aim was to investigate the environmental perception of the park by residents in São José do Goiabal, a municipality located in the vicinities of the park, by performing semi-structured interviews to analyze the influence of different variables. Data showed that gender, social class and age did not determine the frequency of park visitation. Furthermore, wild game hunting proved to be a common practice, recognized by the population, and primarily motivated by leisure and a taste for wild meat. The development of environmental education projects involving students from the basic education network is the most influential factor in the knowledge and appreciation of the park. We suggest the strong need of implementation of environmental education programs, especially towards the younger population, so that they become partners in conservation purposes.

Keywords: Environmental perception. Rio Doce State Park. Regional biodiversity conservation.

\footnotetext{
${ }^{1}$ Mestre em Ecologia Conservação e Manejo da Vida Silvestre - Universidade Federal de Minas Gerais (UFMG), Belo Horizonte, Brasil, biologaguedes@gmail.com

2 Doutoranda do Programa de Pós Graduação em Ecologia Conservação e Manejo da Vida Silvestre - Universidade Federal de Minas Gerais (UFMG), Belo Horizonte, Brasil, maionewf@hotmail.com

3 Professora do Programa de Pós Graduação em Ecologia Conservação e Manejo da Vida Silvestre - Universidade Federal de Minas Gerais (UFMG), Belo Horizonte, Brasil, maia@icb.ufmg.br

4 Professora do Programa de Pós Graduação em Ecologia Conservação e Manejo da Vida Silvestre - Universidade Federal de Minas Gerais (UFMG), Belo Horizonte, Brasil, dodoradrumondbh@gmail.com

5 Professor do Programa de Pós Graduação em Ecologia Conservação e Manejo da Vida Silvestre - Universidade Federal de Minas Gerais (UFMG), Belo Horizonte, Brasil, barbosa@icb.ufmg.br
} 


\section{PERCEPCIÓN AMBIENTAL DE LOS HABITANTES DE SÃO JOSÉ DO GOIABAL SOBRE EL PARQUE ESTADUAL DE RIO DOCE: LA INFLUENCIA DE LAS VARIABLES GÉNERO, EDAD, CLASE SOCIAL Y ESCOLARIDAD}

Resumen: El Parque Estadual de Rio Doce (PERD) fue la primera unidad de conservación creada en Minas Gerais y es una de las mayores áreas remanentes de Mata Atlántica en el país. El objetivo de este estudio fue investigar en São José do Goiabal, municipio circunvecino al parque, la percepción de los habitantes sobre el PERD analizando, a través de entrevistas semiestructuradas, la influencia de diferentes variables. Los datos mostraron que género, clase social y edad no determinan la frecuencia de visita. La caza a animales silvestres se mostró una práctica común, reconocida por la población y motivada principalmente por el ocio y apreciación de la carne. El desenvolvimiento de proyectos de Educación Ambiental envolviendo alumnos de la red básica de educación es el factor que más influencia el conocimiento y valoración del PERD. Tales constataciones sugieren la necesidad de la implantación de programas de Educación Ambiental dirigidos principalmente a los niños y jóvenes, haciéndolos colaboradores de los propósitos de conservación de la biodiversidad en la región.

Palabras clave: Percepción ambiental. Parque Estadual de Rio Doce. Conservación de la biodiversidad regional.

\section{Introdução}

Segundo Faggionato (2011), percepção ambiental é a tomada de consciência sobre os valores e problemas ambientais, ou seja, o ato de perceber o ambiente em que se está inserido, aprendendo a proteger e zelar pelo mesmo.

No Brasil, percebe-se um distanciamento entre a população e o meio ambiente, em razão do próprio quadro conceitual da política ambientalista oficial, caracterizado pela falta de iniciativa do governo na implementação de políticas ditadas pelo binômio da sustentabilidade e do desenvolvimento (JACOBI, 2003; MARTINE, 1993), o que leva a uma separação entre as condições de vida da população e as atividades econômicas. O resultado é a falta de integração entre os processos humanos e naturais, o que contribui para a destruição e degradação do ambiente natural. A compreensão incisiva sobre esse distanciamento pode ser obtida através de pesquisas sobre a percepção ambiental dos envolvidos nesse processo, pois esta se mostra como uma importante ferramenta política, por revelar e contextualizar a realidade local, fornecendo subsídios ao planejamento e à gestão, evitando ou minimizando os conflitos provenientes de ações incoerentes com as realidades.

Ferreira (2005) verificou na Estação Ecológica de Jureia-Itatins, em Iguape (SP), a correlação entre a existência de conflitos sociais decorrentes das restrições provenientes da política ambiental e a percepção ambiental de cinco grupos socioculturais envolvidos na gestão da unidade de conservação (UC). Os resultados da pesquisa indicaram que as diferentes percepções ambientais estavam mais diretamente atreladas aos conflitos provenientes de diferentes políticas externas interessadas no manejo do parque. Bezerra et al. (2008) pesquisaram na Estação Ecológica de Caetés, em Recife (PE), a percepção de alunos e professores sobre essa unidade de conservação para colher subsídios para um programa de Educação Ambiental. Os resultados mostraram que os alunos não tinham clareza da importância da UC na paisagem regional, tampouco da importância desta para a qualidade de vida local. Para os professores, foi possível observar um distanciamento da compreensão ambiental e pouca interação e conhecimento com relação à UC. Silva, Cândido e Freire (2009) identificaram as percepções e conceitos de populações do entorno da Estação Ecológica do Seridó, em Serra Negra do Norte (RN), sobre 
essa UC e constataram que as pessoas conheciam os problemas e indicaram soluções para os mesmos, porém, pelo fato de a UC ser uma instituição governamental, colocavam a maior parte da responsabilidade de atitudes e estratégias para a sua conservação no próprio governo, não trazendo para si a responsabilidade de proteger a Estação Ecológica.

O Parque Estadual do Rio Doce (PERD), criado em 1944, destaca-se por ser a primeira unidade de conservação de proteção integral do estado de Minas Gerais, além de ser o maior remanescente de Mata Atlântica no estado. Conserva porção importante do sistema lacustre do Médio Vale do Rio Doce (c. 51 lagos) e constitui-se numa das maiores áreas remanescentes do bioma Mata Atlântica no Brasil, com 35.976,43 ha. Em 2010 foi incluído como sítio Ramsar, especialmente por conter parcela expressiva de lagos naturais do sistema lacustre do médio Rio Doce (RAMSAR LIST, 2011). O PERD está localizado em uma região denominada Vale do AçO, no leste do estado de Minas Gerais, que inclui os municípios de Timóteo, Marliéria e Dionísio e é circunvizinho de mais seis municípios, entre eles São José do Goiabal, onde foi realizado este estudo.

Apesar de importante região econômico-financeira de Minas Gerais, as atividades desenvolvidas no Vale do Aço trouxeram também problemas ambientais consideráveis para a região, com destaque para a poluição dos recursos hídricos e do ar, a intensificação da erosão de imensas áreas e consequente assoreamento dos cursos d'água e perda de biodiversidade. Além disso, as 33 áreas urbanizadas e a degradação ambiental intensa no seu entorno tornam o parque uma "ilha de Mata Atlântica" circundada por extensas plantações de Eucalyptus spp e pastagens degradadas, em sua maioria (BRITO; OLIVEIRA; JUNQUEIRA, 1997).

Em 2000, com a implantação do projeto PELD-UFMG (Pesquisas Ecológicas de Longa Duração), projetos de Educação Ambiental vêm sendo realizados com o intuito de aproximar a população do seu entorno das riquezas ambientais ainda preservadas nessa unidade de conservação. Assim, atividades têm sido desenvolvidas com os visitantes e a população do entorno, por iniciativa da administração do parque e de projetos desenvolvidos por centros educacionais, como, por exemplo, o programa "Educar para a Ação Ambiental". Esse projeto atua desde o ano 2000, interligando as comunidades locais e o PERD e traduzindo, para essas comunidades, as informações obtidas pelas pesquisas realizadas na região (MAIA-BARBOSA et al., 2003) .

Outros projetos de Educação Ambiental já foram desenvolvidos no PERD. Em 2004, uma primeira tentativa de valoração do capital natural do PERD através da atribuição de valores econômicos aos serviços ecossistêmicos desenvolvidos na UC foi feita por Mikhailova e Barbosa (2004). Coelho (2009) propôs, por exemplo, incentivar a conservação da biodiversidade e a melhoria da qualidade de vida da população residente no assentamento Chico Mendes II, criado em 2002 e vizinho da unidade de conservação.

O presente trabalho teve por objetivo investigar a percepção dos moradores do município de São José do Goiabal sobre o Parque Estadual do Rio Doce e verificar se o conhecimento e identificação com o parque são influenciados pelas seguintes variáveis: gênero, classe social, idade e escolaridade. As informações aqui obtidas poderão ajudar na implantação de projetos ou atividades direcionados a grupos específicos identificados pelo trabalho.

\section{Material e métodos}

O estudo foi realizado no município de São José do Goiabal (19² 55' 44" S; $\left.42^{\circ} 42^{\prime} 18^{\prime \prime} \mathrm{W}\right)$, que tem uma área total de $184.511 \mathrm{~km}^{2}$ e população estimada de 5.636 habitantes, sendo 2.732 homens e 2.904 mulheres (IBGE, 2010). O município situa-se a $26 \mathrm{~km}$ do PERD, sendo limítrofe aos municípios de Dionísio, São Domingos do Prata, Rio Casca e São Pedro dos Ferros. A taxa de alfabetização do município é de 84,3\% e seu Índice de Desenvolvimento Humano (IDH) é de 0,685. Entre os municípios do entorno do PERD, São José do Goiabal é o 
que apresenta a maior incidência de pobreza (43,48\%), comparado a Marliéria (18,96\%), Dionísio $(41,42 \%)$ e Timóteo $(21,07 \%)$ (IBGE, 2003).

A pesquisa foi dividida em duas fases: i) observação direta das relações entre a comunidade de São José do Goiabal e a natureza em geral, mais especificamente com o PERD; ii) entrevistas semiestruturadas realizadas com 102 moradores desse município. Dados gerais sobre os entrevistados foram também anotados (nome, gênero, idade e renda mensal).

Para a análise dos dados coletados foi aplicado o teste do qui-quadrado utilizando-se o programa Statistica, versão 8.

\section{Resultados e discussão}

\section{Perfil do público amostrado}

A idade do público entrevistado variou de 7 a 82 anos, sendo a maioria (60\%) do sexo feminino. Dos entrevistados apenas $13 \%$ possuíam renda familiar superior a quatro salários mínimos e cursaram o ensino superior (Figura 1).

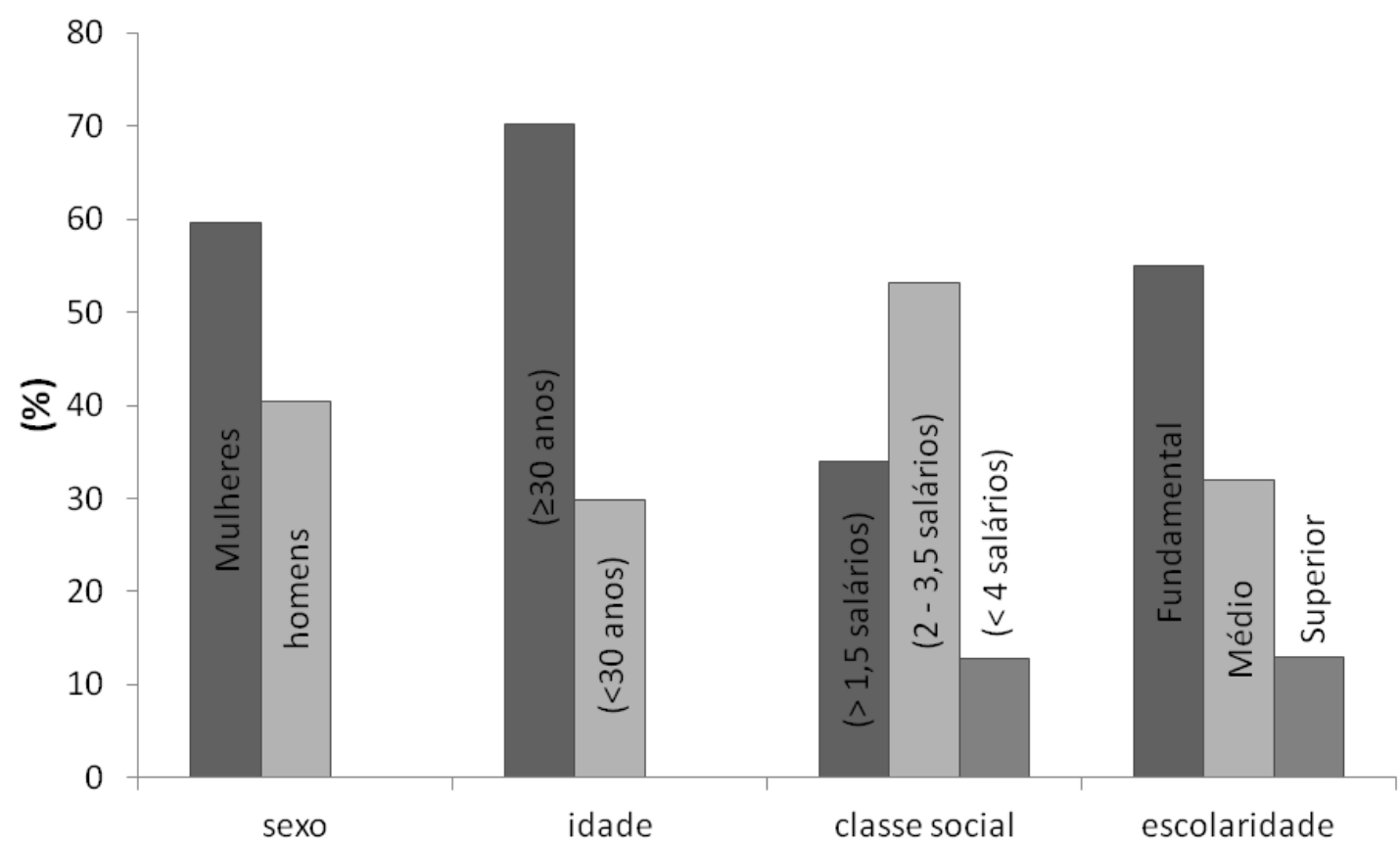

Figura 1. Perfil dos entrevistados em São José do Goiabal (\%) em relação ao gênero, idade, classe social e escolaridade.

Segundo os dados do Programa das Nações Unidas para o Desenvolvimento (PNUD, 2000), o IDH de São José do Goiabal é 0,685, o que coloca o município na 3.234 posição entre as 5.507 cidades brasileiras. Quando se leva em consideração a renda e longevidade, o IDH é ainda menor $(0,579$ e 0,656, respectivamente).

Para o critério escolaridade, São José do Goiabal apresenta um IDH um pouco mais elevado $(0,82)$, mas que ainda o coloca na $2.238^{\circ}$ posição do ranking de cidades brasileiras. A partir das entrevistas realizadas e dos dados do PNUD descritos, pôde-se perceber que se trata de uma comunidade com muitos problemas econômico-sociais, falta de valorização ambiental e ações que promovam o equilíbrio dinâmico da natureza da cidade e entorno. Soares, Bensuan e Ferreira Neto (2002) confirmam que, quando uma população está fragilizada socioeconomicamente, torna-se difícil o envolvimento dos moradores da região para discutir soluções relativas à conservação e ao desenvolvimento. 


\section{Percepção do PERD pelos moradores}

\section{Visitação de moradores ao PERD}

Do total de moradores entrevistados 39,6\% nunca visitaram o parque e 49,5\% visitam-no uma ou duas vezes por ano, sendo a frequência de visitação independente do gênero, classe social ou idade. No entanto, foi obtida uma relação positiva $(p<0,05)$ entre escolaridade e frequência de visitação ao parque. Entrevistados que cursaram apenas o ensino fundamental nunca foram ao PERD $(77 \%)$ ou foram apenas uma ou duas vezes ao longo da vida (45\%), ao passo que aqueles com nível superior relataram utilizar a área da unidade de conservação com frequência $(60 \%)$. Esses dados permitem supor uma importante contribuição da escola para a promoção da valorização da unidade de conservação e do contato com a natureza como uma forma de lazer (Figura 2).

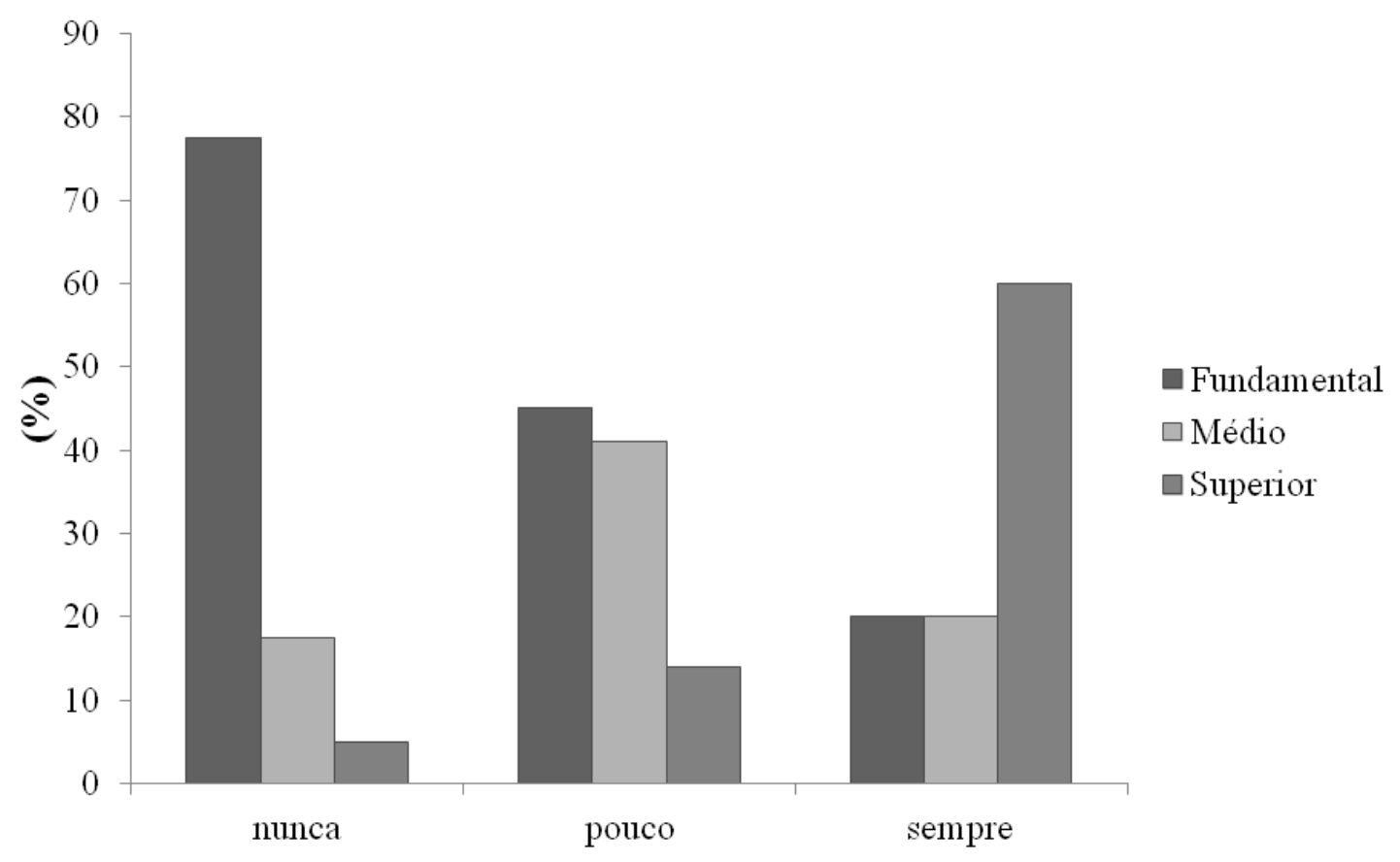

Figura 2. Relação entre frequência de visitação ao PERD e escolaridade da população de São José do Goiabal.

Quando perguntados sobre o que fazem quando visitam o parque, $70 \%$ dos entrevistados citaram atividades relacionadas à contemplação da natureza e descanso. Os demais (30\%) utilizam a área para atividades de lazer, como fazer churrasco e nadar. A contemplação da natureza foi a atividade mais citada pelas mulheres $(81,3 \%)$, pelos jovens $(84,4 \%)$, pelos indivíduos de baixa renda $(82,3 \%)$ e entre pessoas com somente ensino fundamental ou nele matriculado $(76,9 \%)$. Resultados similares foram obtidos em pesquisas em parques urbanos, em que atividades relacionadas com o contato e contemplação da natureza são as preferidas pelos visitantes (MENDES; SOUZA; TABANEZ, 2007), sendo a vegetação o componente da paisagem que mais desperta admiração (FREITAS; MAGALHÃES; GUAPYASSÚ, 2002). Entretanto, diferentemente dos parques urbanos, a prática de atividades físicas não foi citada entre os visitantes do PERD, o que pode ser justificado pela ausência de instalações físicas para a prática de esportes.

Foi possível verificar que moradores de menor renda fazem pouca $(51,5 \%)$ ou nenhuma visita $(48,5 \%)$ ao PERD e os jovens são levados normalmente pela escola ou por empresas $(58,7 \%)$. Desse modo, as visitas ocorrem com pouco tempo disponível para outras atividades e podem restringir-se à observação da paisagem. Já as pessoas de maior renda normalmente têm 
seu próprio meio de transporte e podem levar seus aparatos para atividades de lazer, como churrasco e piquenique. Para muitas pessoas uma viagem de recreação a um parque ou lago nas proximidades é possível em um fim de semana, mas uma viagem mais longa ou determinadas atividades de lazer são imediatamente limitadas pelo seu custo. Dessa forma, a disponibilidade financeira é um fator que restringe ou encoraja a participação em atividades recreativas (DOUGLASS, 1972 apud TAKAHASHI, 1987).

Entre as pessoas que já foram ao PERD, 38\% já visitaram neste alguma trilha interpretativa. Desse percentual, a maior parte $(74 \%)$ é jovem do ensino fundamental e médio e já participou de projetos de Educação Ambiental, o que reflete a importância desses projetos em fornecer oportunidade aos jovens de participar de uma trilha orientada. Mikhailova e Barbosa (2004), ao verificarem as principais atividades dos turistas durante sua visita ao PERD, perceberam que 35\% das visitas são provenientes de projetos de Educação Ambiental realizados no local, dado que confirma a importância de tais projetos.

\section{Importância do PERD para os moradores de São José do Goiabal}

A unidade de conservação foi lembrada por $20 \%$ dos entrevistados como um local de beleza, descanso e de preservação da natureza. Apenas 3\% relataram a possibilidade de uso da área para atividades ligadas ao ensino e produção do conhecimento (em relação à vegetação, por exemplo). A falta de estrutura do município para fornecer lazer, acesso e divulgação foi lembrada por $14 \%$ dos entrevistados, e $59 \%$ não se expressaram por não saberem a resposta ou por não conhecerem o PERD. Alguns relatos reforçam a ideia do desconhecimento sobre o PERD, como a existência de lagoas sujas e muitas plantações de eucaliptos, ameaçando a natureza. As lagoas apontadas nessas declarações estão fora da área do PERD, ou seja, alguns dos entrevistados não sabem nem os limites da unidade de conservação. Outras pessoas não frequentam ou não permitem que as crianças visitem o parque com medo de que haja riscos e ameaças variados, como, por exemplo, ataques de onças, afogamentos ou até mesmo furtos e raptos.

Coelho (2009), ao pesquisar a representatividade da população do assentamento Chico Mendes II, localizado a $3 \mathrm{~km}$ do limite do PERD, verificou que $80,9 \%$ das famílias entrevistadas nunca tinham visitado a área. De forma geral, percebe-se grande distanciamento entre a população de São José do Goiabal e o parque, uma realidade que é também provável para outros municípios. Como exemplo, pode-se citar o Parque Nacional da Serra da Canastra (PNSC), que foi criado sem que houvesse alocação de recursos para sua regularização fundiária e sem o conhecimento da população a respeito de suas implicações. A implantação do parque foi marcada pela condução das desapropriações e desocupações das terras, que provocaram conflitos desnecessários entre os órgãos encarregados pelo gerenciamento e a população. Esses fatos fizeram com que os moradores, produtores rurais e vizinhos do parque criassem certa hostilidade e revolta em relação à prevenção e utilização do fogo, inviabilizando, assim, uma proteção efetiva dos ecossistemas a serem preservados pelo PNSC (OLIVEIRA, 1992).

Lima (2001) salienta que, quando participa da criação de uma unidade de conservação, a comunidade se torna aliada na preservação daquele ambiente. A criação do Parque Estadual da Serra do Brigadeiro é um exemplo disso, pois a participação dos agricultores e das organizações durante a criação foi fundamental para a adaptação de seus limites e restrições, evitando conflitos com a população local. Na proposta inicial pelo Decreto-Lei de 1988, mais de 400 famílias seriam desapropriadas, o que causaria diversos problemas sociais. Nota-se que as populações, tradicionais ou não, residentes no entorno das áreas protegidas são consideradas sempre como um problema, nunca como parte integral das soluções possíveis (BONFIM, 2006).

\section{Avaliação da percepção dos moradores sobre a caça}

\section{A caça de animais silvestres no PERD e seu entorno}


Durante a caminhada de reconhecimento da área, foi registrado o descarte de uma carcaça de tatu (Dasypus novemcinctus) em um lote vago cercado por residências, o que indica a prática do uso de animais silvestres na alimentação (Figura 3).

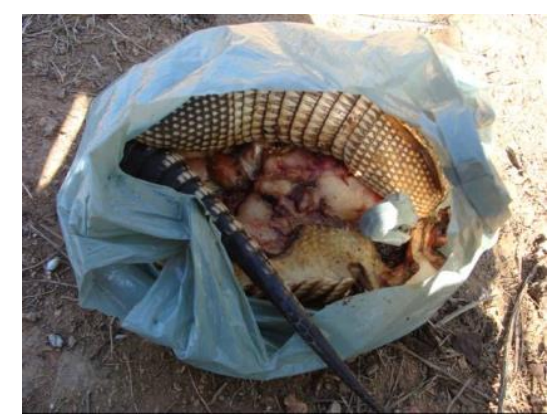

Figura 3. Carcaça de tatu (Dasypus novemcinctus) descartada em lote vago em São José do Goiabal, MG. Foto de Maione Wittig Franco.

Com a confirmação da atividade de caça, procurou-se, durante as entrevistas semiestruturadas, abordar aspectos sobre essa prática ilegal. Foi possível coletar informações sobre a caça praticada dentro e no entorno do PERD e obter relatos sobre as demandas e práticas dessa atividade. Alguns exemplos dos relatos obtidos são descritos a seguir:

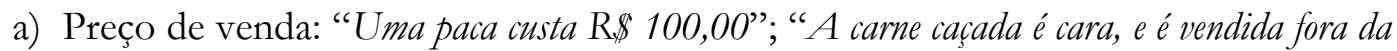
cidade, muita gente compra".

b) Frequência: "Ontem mesmo me ofereceram carne de anta"; "Carne boa, gente de Ipatinga vem para a casa da sogra pra caçar, vai caçador próximo do meu sítio".

c) Preferência: "O tatu é muito apreciado pela sua carne"; "A paca tem carne muito boa".

d) Necessidade: "Falta de consciência, têm dinheiro para comprar e preferem caşar"; "Quem caça não tem vergonha na cara".

e) Fiscalização: "A caça está acabando devido à polícia militar”; "Há muita fiscalização, até mesmo pelo próprio PERD”.

Ao analisar-se o conhecimento da população sobre a existência da caça de animais silvestres no parque e seu entorno, percebe-se que 60\% dos entrevistados reconheceram a existência da caça, 34\% não confirmaram e $6 \%$ preferiram não se manifestar. Durante as entrevistas percebeu-se certo receio dos moradores ao afirmarem a existência da atividade, o que mostra a percepção sobre a ilegalidade da caça. Coelho (2009), ao fazer pesquisa semelhante com moradores do assentamento Chico Mendes II (vizinho do PERD), verificou que a maioria dos entrevistados $(26,61,9 \%)$ acredita que ainda é praticada a caça na região. Em São José do Goiabal, ao analisar-se a relação das diferentes variáveis de influência, perceberam-se opiniões similares entre os diferentes gêneros e idades dos entrevistados e opiniões diferentes conforme classe social e escolaridade, sendo as pessoas de renda salarial média (45\%) e ensino fundamental $(52 \%)$ as que mais confirmam a existência da caça (Tabela 1$)$. 
Tabela 1. Frequência do status de percepção dos moradores de São José do Goiabal sobre a caça na região. As frequências de respostas foram avaliadas em relação às variáveis gênero, idade, classe social e escolaridade pelo teste do qui-quadrado $(\mathrm{n}=101)$.

\begin{tabular}{|c|c|c|c|c|c|c|c|c|c|c|}
\hline $\begin{array}{c}\text { Qui-quadrado } \\
\text { (p) }\end{array}$ & Gê & ero & & & & 0,13 & & & 0,62 & Ide \\
\hline $\begin{array}{c}\text { Há caça em São } \\
\text { José do Goiabal e } \\
\text { região? }\end{array}$ & 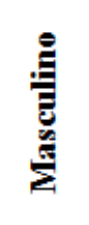 & 竞 & 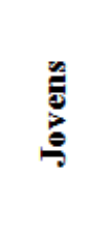 & $\frac{\hat{E}}{\frac{E}{E}}$ & 䒿 & 密 & $\stackrel{\text { E }}{\xi}$ & 焉 & 宫 & 竞 \\
\hline Sim (\%) & 58,8 & 62,0 & 65,4 & 55,1 & 51,5 & 57,1 & 84,2 & 56,1 & 67,8 & 61,5 \\
\hline Não (\%) & 31,4 & 34,0 & 25,0 & 40,8 & 42,4 & 32,7 & 15,8 & 38,6 & 22,6 & 30,8 \\
\hline Desconhece (\%) & 9,8 & 04,0 & 9,7 & 4,1 & 6,1 & 10,2 & 0,0 & 5,3 & 9,7 & 7,7 \\
\hline
\end{tabular}

Com os relatos e informações obtidas percebe-se que a caça de animais silvestres é uma prática comum e reconhecida pela população de São José do Goiabal. Entre os animais mais caçados estão a paca (Agouti paca), o tatu (Dasspus sp) e a anta (Tapirus terrestris). Essas espécies foram as mais citadas ao se averiguar a comercialização de carne de animais silvestres. Entre as pessoas que reconheceram a existência da caça na cidade, 93\% $(n=57)$ deram sua opinião sobre os motivos que levam as pessoas a caçar (Figura 4).

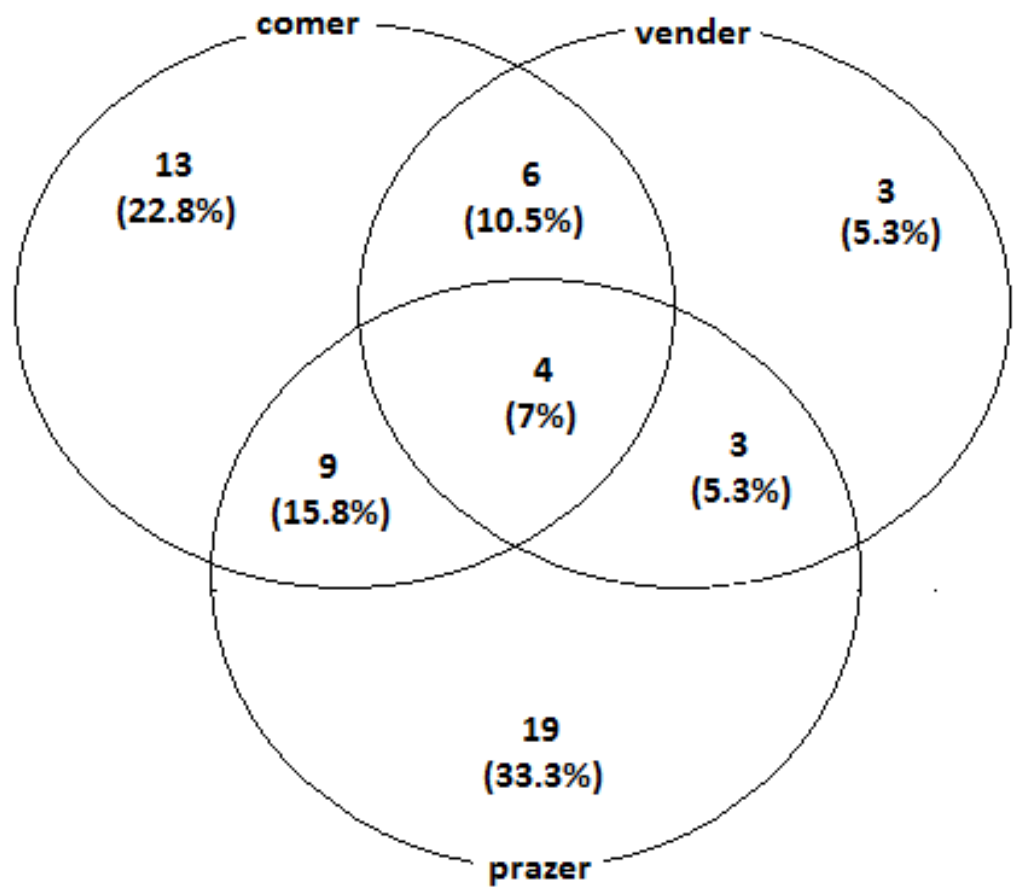

Figura 4. Opinião dos entrevistados de São José do Goiabal sobre os motivos que levam as pessoas a caçar (n=57).

A caça esportiva foi apontada por $61 \%$ dos entrevistados como o principal motivo para a atividade na região, seguida do uso dos animais na alimentação $(56,1 \%)$ e comércio $(28,1 \%)$. 
Alguns dos entrevistados relataram a presença de pessoas de outros municípios para caçar nas regiões próximas ao parque, como uma atividade de lazer nos finais de semana.

Embora durante a entrevista algumas pessoas tenham demonstrado receio ao confirmarem a venda de animais caçados, $28,1 \%$ reconhecem essa prática como um dos motivos da caça. O conhecimento da ilegalidade dessa atividade pelos entrevistados pode justificar o baixo número de respostas obtidas para essa questão.

As opiniões sobre os motivos que levam as pessoas a caçar não foram influenciadas pelas variáveis gênero $(\mathrm{p}=0,51)$, idade $(\mathrm{p}=0,10)$ e classe social $(\mathrm{p}=0,14)$. A escolaridade, por sua vez, influencia significativamente as opiniões dos entrevistados sobre a caça $(\mathrm{P}>0,05)$, e, entre os motivos que levam à existência da caça, a resposta "comer" foi apresentada pela maioria das pessoas com ensino fundamental $(62,5 \%)$. A resposta "prazer" foi mais presente $(48,6 \%)$ entre as pessoas com ensino médio. Já o fato de se caçar para vender foi reconhecido por 37,5\% das pessoas que apresentam nível superior (Figura 5).

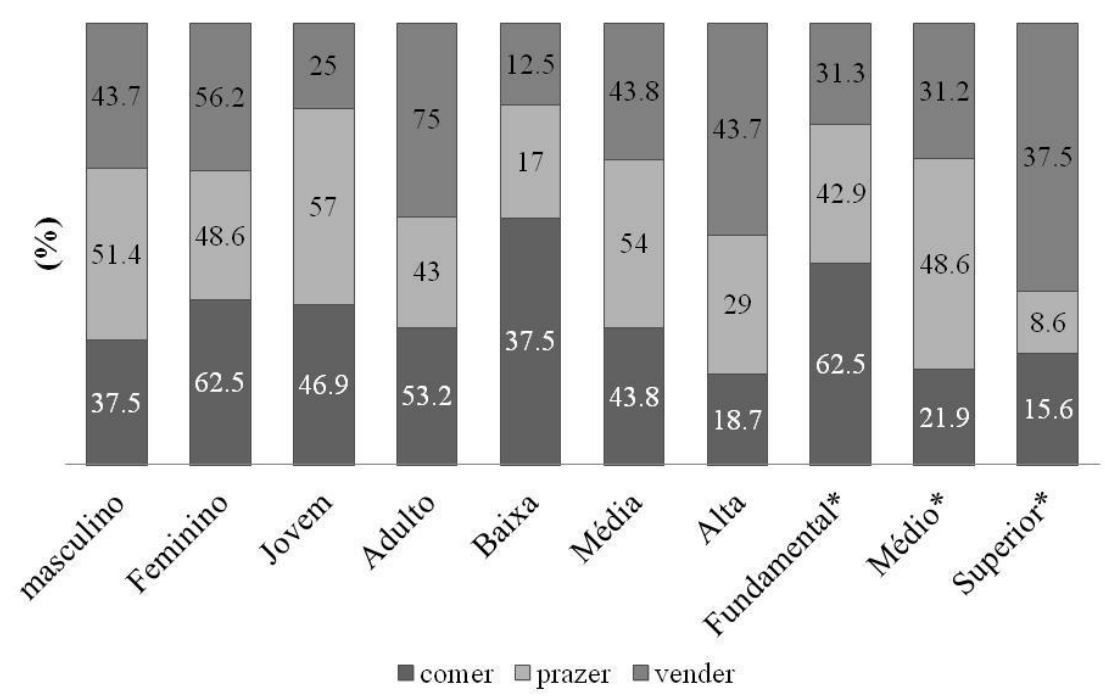

Figura 5. Opiniões dos moradores de São José do Goiabal sobre os motivos que levam as pessoas a caçar, segundo as variáveis: gênero, idade (Jovem e Adulto), classe social (Baixa, Média e Alta) e escolaridade (Fundamental, Médio e Superior). $\left(^{*}\right)$ indica frequências diferentes pelo teste do qui-quadrado.

\section{Conclusão}

Os moradores de São José do Goiabal, em sua maioria, não reconhecem a importância do PERD como uma unidade de conservação. Uma fração menor da população vê positivamente sua existência para a proteção da natureza. O grau de escolaridade é o fator que mais influencia a visitação ao PERD, e os projetos de Educação Ambiental têm representado a principal oportunidade de visitação entre os estudantes do ensino fundamental e médio. Esses resultados demonstram a necessidade de divulgação do parque e de desenvolvimento de projetos de Educação Ambiental transformador para que essa unidade de conservação seja valorizada e reconhecida. A partir do maior reconhecimento da população e valorização do parque, problemas frequentemente encontrados, como o assoreamento, poluição de rios por esgotos e a caça de animais silvestres, poderiam ser mais facilmente controlados ou evitados.

\section{Referências}


BEZERRA, Tatiana Marcela de Oliveira; FELICIANO, Ana Lúcia Patriota; ALVES, Ângelo Giuseppe Chaves. Percepção ambiental de alunos e professores do entorno da Estação Ecológica de Caetés. Biotemas, Recife, v. 21, n. 1, p. 147-160, 2008.

BONFIM, Verônica. Diagnóstico do uso do fogo no entorno do Parque Estadual da Serra do Brigadeiro (PESB), MG. 58 p. Dissertação (Mestrado em Ciência Florestal) - Universidade Federal de Viçosa, Viçosa, MG, 2006.

BRITO, Fausto R. A.; OLIVEIRA, Ana Maria H. C.; JUNQUEIRA, André C. A ocupação do território e a devastação da Mata Atlântica. In: PAULA, João Antônio de (Ed.). Biodiversidade, população e economia: uma região de Mata Atlântica. Belo Horizonte: UFMG/CEDEPLAR/ECMXC/PADCT/CIAMB, 1997. p. 48-89.

COELHO, Paula Ribeiro. Projeto de Assentamento Chico Mendes II: uma parceria possível entre Reforma Agrária e Conservação da Mata Atlântica. 97 p. Dissertação (Mestrado) - Instituto de Ciências Biológicas, Universidade Federal de Minas Gerais, Belo Horizonte, 2009.

FAGGIONATO, Sandra. Percep̧ão ambiental. 2011. Disponível em: <http://educar.sc.usp.br/biologia/textos/m_a_txt4.html>. Acesso em: 10 ago. 2011.

FERrEIRA, Carolina Peixoto. Percepscão Ambiental na Estação Ecológica de Juréia Itatins. 161 p. Dissertação (Mestrado em Ciências Ambientais) - Universidade de São Paulo, São Paulo, 2005.

FREITAS, Welington Kiffer de; MAGALHÃES, Luis Mauro Sampaio; GUAPYASSÚ, Maísa dos Santos. Potencial de uso público do Parque Nacional da Tijuca. Acta Scientiarum, Maringá, v. 24, n. 6, p. 1833-1842, 2002.

IBGE. Censo Demográfico@cidades. 2003. Disponível em: <http://www.ibge.gov.br/cidadesat/topwindow.htm?1>. Acesso em: 22 dez. 2011.

JACOBI, Pedro. Educação Ambiental, cidadania e sustentabilidade. Cadernos de Pesquisa, São Paulo, n. 118, p. 189-205, 2003.

LIMA, Gumercindo Souza. O SNUC - Sistema Nacional de Unidades de Conservação: avanços, falhas e desafios. Ação Ambiental, ano 4, n. 19, p. 8-10, ago./set. 2001.

MAIA-BARBOSA, Paulina Maria; BARBOSA, Francisco Antônio Rodrigues; GUERRA, Cláudio B.; VIANA, Flávia Elizabeth de Castro; TORRES, Fabiane; PENA, Patrícia Campos; BARBOSA, Tatiane Cristina Reis; ALONSO, Rodrigo Soares. Educar para a ação ambiental. Encontro de extensão da UFMG. Anais... Belo Horizonte: Universidade Federal de Minas Gerais, 2003. p. 164-169.

MARTINE, George. População, meio ambiente e desenvolvimento: o cenário global e nacional. In: __ (Org.). População, meio ambiente e desenvolvimento: verdades e contradições. Campinas: Editora da Unicamp, 1993. p. 21-41.

MENDES, Adriana Fernandes; SOUZA, Sonia Aparecida de; TABANEZ, Marlene Francisca. A Trilha Interpretativa das Árvores Gigantes do Parque Estadual de Porto Ferreira na modalidade autoguiada. Rev. Inst. Flor., São Paulo, v. 19, n. 2, p. 173-188, dez. 2007. 
MIKHAILOVA, Irina; BARBOSA, Francisco Antônio Rodrigues. Valorando o capital natural e os serviços ecológicos de unidades de conservação: o caso do Parque Estadual do Rio Doce-MG, Sudeste do Brasil. Belo Horizonte: UFMG/CEDEPLAR, 2004. (Texto para discussão, n. 230).

OLIVEIRA, Lyria Chaves de Andrade. Produtores rurais e parque nacional: estudo de caso na Serra da Canastra-MG. Lavras: ESAL, 1992. 121 p.

PNUD. Atlas do Desenvolvimento Humano. 2000. Disponível em: <http://www.pnud.org.br/atlas/ranking/IDHM\%2091\%2000\%20Ranking\%20decrescente\%20( pelos $\% 20$ dados\%20de\%202000).htm >. Acesso em: 22 dez. 2011.

RAMSARLIST. The List of Wetlands of International Importance 2011. 2011. Available from: < http://www.ramsar.org/pdf/sitelist.pdf >. Cited: 23 Dec. 2011.

SILVA, Thaise Sousa da; CÂNDIDO, Gesinaldo Ataíde; FREIRE, Eliza Maria Xavier. Conceitos, percepções e estratégias para conservação de uma Estação Ecológica da Caatinga Nordestina por populações do seu entorno. Sociedade \& Naturez̧a, Uberlândia, v. 21, n. 2, p. 2337, 2009.

SOARES, Maria Clara Couto; BENSUAN, Nurit; FERREIRA NETO, Paulo Sérgio. Entorno de Unidades de Conservação: Estudo de Experiências com UCs de Proteção Integral. Rio de Janeiro: FUNBIO, 2002.

TAKAHASHI, Leide Yassuco. Avaliação da visitação e dos recursos recreativos da estrada da Graciosa. 127 p. 1987. Dissertação (Mestrado em Engenharia Florestal) - Setor de Ciências Agrárias, Universidade Federal do Paraná, Curitiba, 1987.

Artigo recebido em 07/11/2012

Artigo aprovado em 22/06/2013 